\title{
Response of land use changes on ecological water diversion in midstream of the Heihe River Basin
}

\author{
Longqiang $\mathrm{Su}^{1, \mathrm{a}}$ \\ ${ }^{1}$ Zhejiang Institute of Hydraulics \& Estuary, Hangzhou 310020, China
}

\begin{abstract}
Based on the land use data in midstream of the Heihe River Basin in 1986, the CLUE-S model was used to simulate the land use distribution in 2000 . In addition, the simulated map was verified by the land use map in 2000 . Then the spatial pattern of land used in 2015 under the scenario without water diversion was simulated. The results show that the CLUE-S model could be applied to simulate the spatial pattern of land use changes in midstream of the Heihe River basin. Under both scenarios, cultivated land and construction land area showed a tendency of increasing. Forestland, pastureland and unused land showed a tendency of decreasing, while the convert tendency from unused land to other land use types was accelerated. The water surface area decreased under the scenario without water diversion, while under ecological water diversion scenario it showed a tendency of increasing. After the implementation of water diversion, the speed was accelerated. Under the scenario without water diversion, the main types of land use changes were cultivated land, pastureland and water surface area . Conversely, they were cultivated land, pastureland and unused land
\end{abstract}

\section{Review}

Land use change is one of the hot issues in the study of global change. As an important part of land use change science, the simulation and prediction model of land use change plays an important role in analyzing the driving force and evolution process of land use change, evaluating the ecological effect of land use change and the decision analysis of land use planning ${ }^{[1]}$. At present, land use change models can be classified into three categories: empirical statistical model based on mathematical regression, conceptual mechanism model based on economic theory and subject behavior, and comprehensive model ${ }^{[2]}$. The CLUE-S model is one of the comprehensive models widely used. Its main advantage is that it can simulate the spatial dynamic change of various land use types at the same time and the land use change under different scenarios. It was widely used in the study of land use change in different regions and has achieved good application effect ${ }^{[3-5]}$.

In northwest China, the ecological environment is fragile and water resource is the main factor that restricts the development of land resource. The Heihe River Basin is a typical arid inland river basin, the total amount of water resources is insufficient, the water affairs contradictions between the basin regions are frequently ${ }^{[6]}$. In view of the water resources problem in the basin, our country started to implement the Heihe river ecological water transfer from 2000, and adjusted the water flow from Zhengyi Gorge to the downstream according to the water sources of the upstream Yingluo Gorge. Since the water distribution, the ecological and environmental in the lower reaches of Heihe river have improved, but the development of oasis agriculture in the midstream has been restricted ${ }^{[7]}$. The uncoordinated matching of soil and water resources has become an important factor restricting the sustainable development of social economy in midstream of the Heihe River Basin. Therefore, this article established CLUE-S model, and the spatial pattern of land use in midstream without water diversion is simulated, and then compare the spatial pattern of land use between the implementation of water diversion and without water diversion, reveal the land use change on the response of ecological water diversion.

\section{Overview of research area}

The Heihe River Basin is located in the middle of the Hexi Corridor, divided into upper, middle and lower reaches by Yingluo Gorge and Zhengyi Gorge. Upstream Qilian Mountain is water conservation forest, midstream Zhangye Basin is oasis agriculture area, and downstream Ejin is desert oasis area. In this paper, we study the midstream of the Heihe River Basin area, including the Minle, Zhangye, Shandan, Linze and Gaotai county, the area is most densely populated, most developed, and where the natural environment is most affected by human activity.

\footnotetext{
a Corresponding author: sulq@zjwater.gov.cn
} 
The midstream of the Heihe River Basin belong to typical temperate continental climate, precipitation is rare and spatiotemporal distribution is not uniform, evaporate strongly. The average annual precipitation is between $110-350 \mathrm{~mm}$, annual evaporation is between $1632-2198 \mathrm{~mm}$. The middle reaches runoff is mainly maintained by the amount of water coming out of the mountains in the upper Qilian Mountains, and the amount of water resources that can be directly utilized in the whole region is about 2.57 billion $\mathrm{m}^{3}$.

\section{Data sources and research methods}

\subsection{Data source and processing}

The data used in this article includes: DEM data with a resolution of $90 \mathrm{~m}$ in Heihe River Basin, Land use data of Heihe River Basin in 1986 and 2000, Land use data of Zhangye city in 2015, Road distribution data set of Heihe River Basin, data set of Zhangye irrigation canal system, river distribution data set of Heihe River Basin, reservoir distribution data set of Heihe River Basin, spatial distribution data set of machine-mining Wells in Zhangye city, soil texture data of Heihe River Basin, soil type data sets of Heihe River Basin in 1980s, population grid data set in Heihe River Basin. Among them, DEM data comes from Geospatial Data Cloud Website, and other data comes from Heihe Project Data Management Center. Due to the spatial distribution of land use in the form of raster, all spatial data need to be transformed into raster data with the same projection system and geographic coordinates, and make sure the size and number of grids are consistent. The geographic coordinate system adopted in this paper is GCS_Krasovsky_1940 and the projection coordinate system is Albers.

The selection of driving factors of land use change should follow the following principles: data availability, quantification of driving factors, spatial differences in the study area, greater correlation with land use change in the study area, data consistency and equal emphasis on natural and socio-economic factors. Taking the above principles into consideration, 12 land use driving factors are selected as follows: distance from river, distance from trunk canal, distance from mechanical well, distance from reservoir, distance from road, distance from residential area, soil type, soil structure, altitude, slope, slope direction and population density. The distance factor is to overlay the land use map of the study area with the layers of rivers, channels, mechanical Wells, reservoirs, roads, etc., and then use the spatial analysis function of GIS to calculate the distance between each grid in the study area and each element. Slope and slope direction are extracted from DEM data by Surface Analysis function of GIS.

\subsection{Research methods}

\subsubsection{CLUE-S model structure}

The CLUE-S model is divided into two independent modules: the non-space requirement module and the space explicit allocation module. Based on the analysis of driving factors of land use change such as nature, social economy, policies and regulations, the non-spatial demand module calculates the demand area of each land use type in the study area over the years. Spatial explicit allocation module uses raster-based systems to allocate land use demands. The CLUE-S model only supports spatial distribution of changes in land use type, and the land use demand module can choose simple trend extrapolation or complex economic model according to the needs of the model. In this paper, the trend extrapolation method is used to obtain the land use demand area for each year between 1986 and 2000 based on the linear interpolation of land use data in the two periods of 1986 and 2000.

\subsubsection{Spatial feature analysis}

In CLUE-S model, the stepwise regression analysis method is adopted to quantitatively analyze and evaluate the relationship between spatial layout of land use and driving factors. The Logistic stepwise regression method is a commonly used method. According to a group of driving factors affecting the spatial layout of land use, the probability of a certain land use type may appear in each grid unit is calculated, so as to explain the relationship between different classes and their driving factors $^{[8]}$. The Logistic regression calculation formula is:

$$
\log \left\{\frac{P_{i}}{1-P_{i}}\right\}=\beta_{0}+\beta_{1} X_{1, i}+\beta_{2} X_{2, i}+\cdots+\beta_{n} X_{n, i}
$$

In the formula, $p$ represents the probability of land use type I appearing in the grid, and $X$ represents the driving factor. Logistic stepwise regression can screen out the factors that have a significant impact on the spatial layout of land use and eliminate the factors that are not significant. As for the verification of Logistic regression effect, the ROC (Relative Operating Characteristics) method proposed by Pontius R.G. is commonly used at present ${ }^{[9]}$. The fitting degree between the simulated spatial layout of land use type and the actual spatial layout is judged according to the Area Under the Curve AUC. The AUC value is between 0.5-1. The larger the value, the stronger the interpretation ability of the driving factor on land use type. Generally speaking, when the AUC is greater than 0.7, the selected driving factors can explain the spatial pattern of land use in the study area more accurately ${ }^{[10]}$.

\subsubsection{Model accuracy test}

Kappa index method is mostly used to test the simulation accuracy of land use change of CLUE-S model ${ }^{[1]}$. The formula is:

$$
\text { Kappa }=\frac{P_{o}-P_{c}}{P_{p}-P_{c}}
$$

In the formula, $P o$ is the proportion of correct simulation; $P c$ is the ratio of expected correct simulation under random conditions; $P p$ is the ratio of the correct simulation under ideally conditions. It is generally believed that when Kappa $\geq 0.75$, the two land use type 
maps have a high consistency; when Kappa $<0.4$, the consistency is poor. In the evaluation of the simulation accuracy of CLUE -S model, the higher the value of Kappa, the higher the model fitting accuracy.

\subsubsection{Scenario setting}

Since the implementation of the Heihe River water distribution policy, in order to realize the water distribution scheme in the main flow area, a series of comprehensive engineering and non-engineering treatment measures have been implemented in the midstream of the river in recent years, which has a great impact on the spatial pattern of land use. In order to analyze the impact of Heihe ecological water transfer on land use change in midstream, two land use scenarios were set: non-water diversion scenario and implementation of ecological water transfer. The nonwater diversion scenario assumes that the land use demand in the middle reaches is not affected by the large-scale water-saving policy after the implementation of ecological water transfer. The demand area of each land use type maintains the same rate of change as that of 1986-2000 before ecological water transfer, and the demand area of each region from 2001 to 2015 is calculated. The change of land use after ecological water transfer is represented by the actual land use data of midstream of Heihe river in 2015.

\section{Results and analysis}

\subsection{Logistic regression analysis}

Because the study of land use change pattern and driving mechanism has obvious scale effect, the choice of appropriate scale is very important to the simulation of land use change. This paper chooses three scales of $200 \times 200 \mathrm{~m}, 500 \times 500 \mathrm{~m}$ and $1000 \times 1000 \mathrm{~m}$ to analysis, draws the ROC curve of the simulation results under different scales, and then chooses the best simulation scale.

By comparison, in $200 \times 200 \mathrm{~m}$ scale the overall goodness of fit of regression equation is the best. The ROC curve and AUC value of each land use type are shown in Figure 1. From the Figure, we can see that the driving factors have the strongest explanatory power for construction land, the AUC value is 0.946. Then the cultivated land (AUC $=0.928)$, unused land (AUC $=$ $0.875)$, forestland $(\mathrm{AUC}=0.864)$ and pastureland (AUC $=0.730$ ). The regression equation has relatively weak ability to simulate the water surface, with a AUC value of 0.698. However, in general, the selected driving factors in the scale of $200 \times 200 \mathrm{~m}$ still have a good interpretation, meet the regression requirements of the model, can be applied to the simulation of land use spatial distribution in the midstream of the Heihe River Basin.

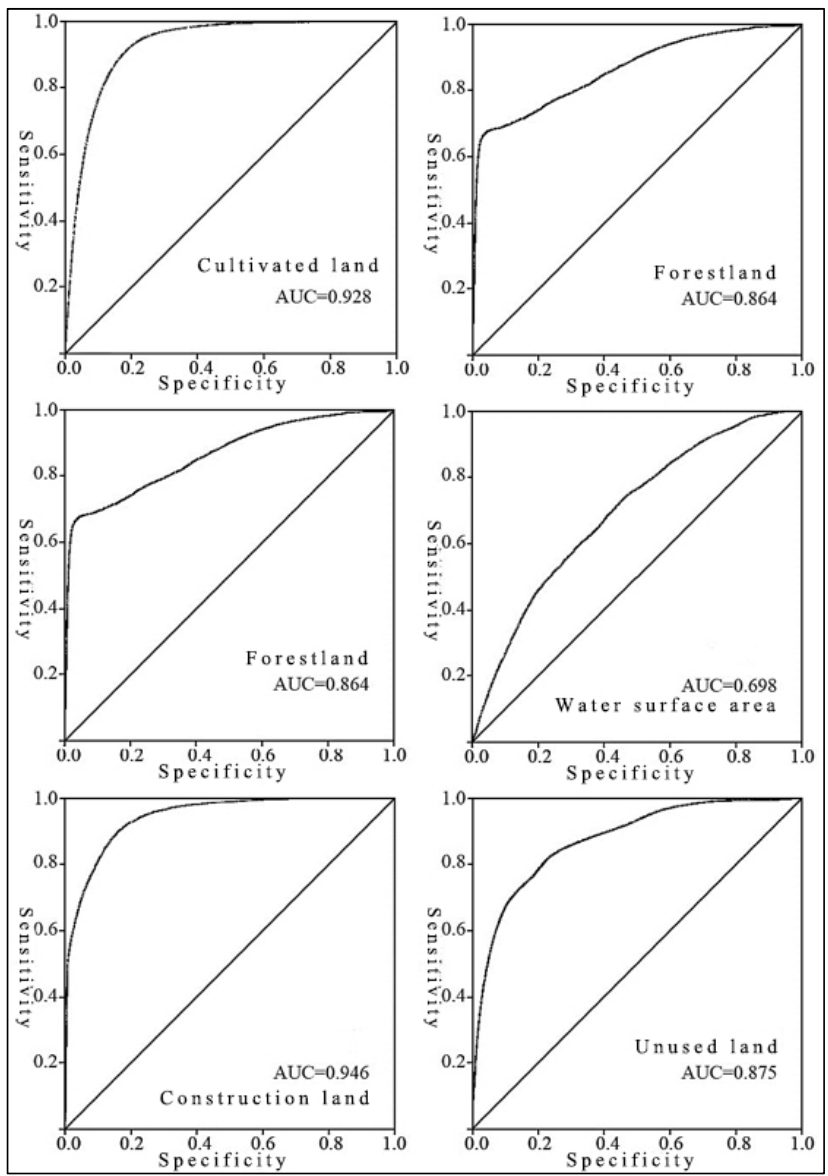

Figure 1. ROC curves and AUC values for different land use types

\subsection{Analysis of model simulation results}

The land use distribution information of 2000 generated by CLUE-S model is stored in ASCII format file. It needs to be converted into grid format file by ArcGIS tool to generate visualized land use spatial pattern simulation map (Figure 2). The accuracy of the simulation results was checked by the actual land use type distribution map in 2000. The number of grids correctly simulated by the model was 359493 , and the total number of grids in the study area was 380576 . The overall accuracy of the simulation was $94.46 \%$, and the Kappa index was 0.934. The results show that the simulated land use distribution map in 2000 is in good agreement with the actual land use distribution map. The CLUE-S model can be applied to the spatial pattern simulation of land use change in the midstream of Heihe River.

\subsection{Response analysis of land use change to water transfer}

Figure 3. is the land use distribution map of the midstream of Heihe River in 2015. The land use map after the implementation of the ecological water transfer is represented by the actual land use data of the midstream of Heihe River in 2015. The land use map under the non-water transfer scenario is simulated by the 
CLUE-S model. Comparing the difference of land use spatial pattern between non-water diversion scenario and ecological water diversion, the response of land use change to ecological water diversion was analyzed from three aspects: land use dynamic degree, land use type conversion and land use degree change.

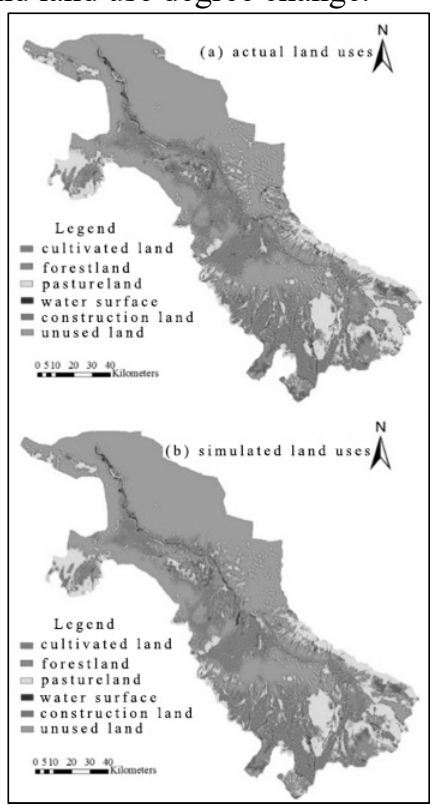

Figure 2. Distribution of land uses in midstream of the Heihe River basin in 2000

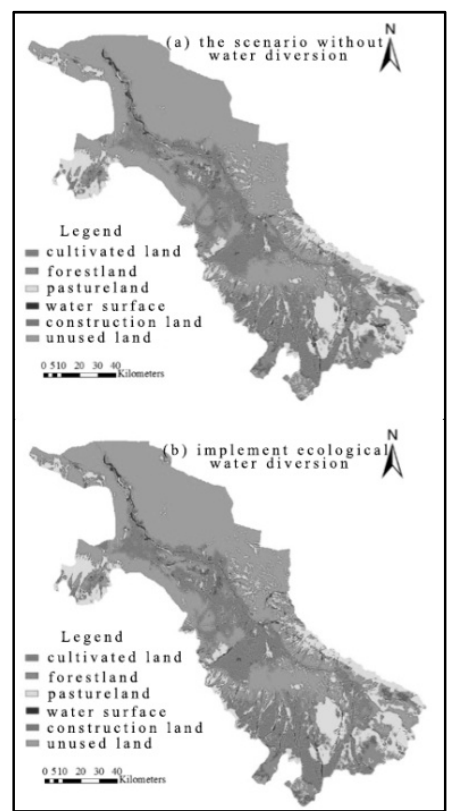

Figure 3. Distribution of land uses in midstream of the Heihe River basin in 2015 under different scenarios

\subsubsection{Dynamic change of land use}

(1) Single land use dynamic degree: express the quantity change of a certain type of land use within a certain time horizon. The formula is:

$$
K=\frac{U_{b}-U_{a}}{U_{a}} \times \frac{1}{T} \times 100 \%
$$

In the formula, $U a$ and $U b$ are the number of land use types in the early and late stages of the study area, respectively; $T$ is the period of study. When $T$ is set to be year, $K$ is the annual change rate of land use in the study period.

Calculating the dynamic index of single land use types in 2000-2015 under two scenarios. The results are shown in Table 1. The negative value represents the type of land use with reduced area and the positive value represents the type of land use with increased area. Under the two scenarios, cultivated land and construction land area showed an increasing trend, ecological water transfer intensified its change trend, land use dynamics increased from $0.48 \%$ and $0.29 \%$ to $1.37 \%$ and $0.57 \%$ respectively. The area of forestland, pastureland and unused land showed a decreasing trend. Ecological water diversion slowed down the decreasing trend of forestland and pastureland, and intensified the conversion of unused land to other land use types. Dynamics of forestland and pastureland changed from $0.23 \%$ and $-0.38 \%$ to $-0.02 \%$ and $-0.18 \%$ respectively. The dynamic degree of unused land increase from $-0.01 \%$ to $-0.55 \%$. The water area showed a decreasing trend under the situation of none- water diversion, but an increasing trend after the implementation of ecological water diversion. The dynamic degree of land use changed from $-0.59 \%$ to $0.14 \%$. The construction and improvement of water diversion irrigation channel after ecological water diversion was one of the reasons for the increase of water surface area.

Table1. Dynamic situation of each land use type in 2015 under two scenarios $(\%)$

\begin{tabular}{ccc}
\hline Land use type & Scenario a & Scenario b \\
\hline cultivated land & 0.48 & 1.37 \\
forestland & -0.23 & -0.02 \\
pastureland & -0.38 & -0.18 \\
water surface & -0.59 & 0.14 \\
construction land & 0.29 & 0.57 \\
unused land & -0.01 & -0.55 \\
\hline
\end{tabular}

(2) Comprehensive land use dynamic degree: express the quantity change of a certain land use type in a period. The formula is:

$$
L C=\frac{\sum_{i=1}^{n} \Delta L U_{i-j}}{2 \sum_{i=1}^{n} L U_{i}} \times \frac{1}{T} \times 100 \%
$$

In the formula, $L U_{i}$ is the area of land use type $i$ in the initial stage of the study, $\Delta L U_{i-j}$ is the absolute value of the area of land use type $i$ converted to other types during the study period, and $T$ is the monitoring period. When $T$ is set to be the year, the value of $L C$ is the annual change rate of land use in the study area.

Under non-water transfer scenario and ecological water transfer, the comprehensive land use dynamic degree of the study area in 2000-2015 were $0.11 \%$ and $0.31 \%$ respectively, which indicated that the land use change speed was accelerated after the implementation of ecological water transfer.

\subsubsection{Land use type conversion}

Land use transfer matrix can quantitatively explain the mutual transformation between land use types, reveal the 
transfer probability between different land types. The formula is:

$$
A=\left[\begin{array}{cccc}
a_{11} & a_{12} & \cdots & a_{1 n} \\
a_{21} & a_{22} & \cdots & a_{2 n} \\
\cdots & \cdots & \cdots & \cdots \\
a_{n 1} & a_{n 2} & \cdots & a_{n n}
\end{array}\right]=a_{i j}
$$

In the formula, $i, j$ represent the land use types at the beginning and end of the study period; $a_{i j}$ is the area of land use type $i$ converted to other land use types.

The transfer matrix of land use between 2000 and 2015 in the two scenarios is obtained by GIS tools. The results are shown in Tables 2 and 3.

Table 2. Transfer matrix of land use types under the scenario without water diversion $\left(\mathrm{hm}^{2}\right)$

\begin{tabular}{|c|c|c|c|c|c|c|c|}
\hline \multirow[b]{2}{*}{2000} & \multicolumn{6}{|c|}{2015} & \multirow{2}{*}{$\begin{array}{c}\text { Total } \\
\text { area in } \\
2000\end{array}$} \\
\hline & $\begin{array}{c}\text { cultivated } \\
\text { land }\end{array}$ & $\begin{array}{c}\text { fores } \\
t- \\
\text { land }\end{array}$ & $\begin{array}{l}\text { pastur } \\
\text {-eland }\end{array}$ & $\begin{array}{c}\text { water } \\
\text { surface }\end{array}$ & $\begin{array}{l}\text { constructi- } \\
\text { on land }\end{array}$ & $\begin{array}{c}\text { unused } \\
\text { land }\end{array}$ & \\
\hline $\begin{array}{l}\text { cultivated } \\
\text { land }\end{array}$ & 325128 & 0 & 0 & 0 & 4 & 76 & 325208 \\
\hline forestland & 740 & $\begin{array}{c}5254 \\
4\end{array}$ & 124 & 0 & 28 & 1768 & 55204 \\
\hline $\begin{array}{c}\text { Pasturelan } \\
\text {-d }\end{array}$ & 24 & 0 & $\begin{array}{c}31395 \\
2\end{array}$ & 0 & 112 & 9048 & 323136 \\
\hline $\begin{array}{c}\text { water } \\
\text { surface }\end{array}$ & 292 & 4 & 216 & 38340 & 60 & 4472 & 43384 \\
\hline $\begin{array}{l}\text { constructi } \\
\text { o-n land }\end{array}$ & 0 & 0 & 0 & 0 & 31092 & 0 & 31092 \\
\hline $\begin{array}{c}\text { unused } \\
\text { land }\end{array}$ & 6836 & 2032 & 2784 & 3760 & 240 & 728628 & 744280 \\
\hline $\begin{array}{l}\text { Total area } \\
\text { in } 2015\end{array}$ & 333020 & $\begin{array}{c}5458 \\
0\end{array}$ & $\begin{array}{c}31707 \\
6\end{array}$ & 42100 & 31536 & 743992 & $\begin{array}{c}152230 \\
4\end{array}$ \\
\hline $\begin{array}{c}\text { Change } \\
\text { area }\end{array}$ & 7812 & -624 & -6060 & -1284 & 444 & -288 & \\
\hline
\end{tabular}

Table 3. Transfer matrix of land use types with water diversion $\left(\mathrm{hm}^{2}\right)$

\begin{tabular}{|c|c|c|c|c|c|c|c|}
\hline \multirow[b]{2}{*}{2000} & \multicolumn{6}{|c|}{2015} & \multirow{2}{*}{$\begin{array}{c}\text { Total } \\
\text { area in } \\
2000\end{array}$} \\
\hline & $\begin{array}{c}\text { cultivated } \\
\text { land }\end{array}$ & $\begin{array}{c}\text { fores } \\
t- \\
\text { land }\end{array}$ & $\begin{array}{l}\text { pastur } \\
\text {-eland }\end{array}$ & $\begin{array}{c}\text { water } \\
\text { surface }\end{array}$ & $\begin{array}{c}\text { Constructi } \\
\text {-on land }\end{array}$ & $\begin{array}{c}\text { unused } \\
\text { land }\end{array}$ & \\
\hline $\begin{array}{l}\text { cultivated } \\
\text { land }\end{array}$ & 321968 & 236 & 1044 & 300 & 872 & 788 & 325208 \\
\hline forestland & 1828 & $\begin{array}{c}5298 \\
4\end{array}$ & 172 & 44 & 32 & 144 & 55204 \\
\hline $\begin{array}{c}\text { Pasturelan } \\
-d\end{array}$ & 6992 & 204 & $\begin{array}{c}31380 \\
8\end{array}$ & 308 & 176 & 1648 & 323136 \\
\hline $\begin{array}{c}\text { water } \\
\text { surface }\end{array}$ & 340 & 12 & 648 & 41312 & 48 & 1024 & 43384 \\
\hline $\begin{array}{c}\text { constructi } \\
0-\mathrm{n} \text { land }\end{array}$ & 1032 & 4 & 56 & 0 & 29980 & 20 & 31092 \\
\hline $\begin{array}{l}\text { unused } \\
\text { land }\end{array}$ & 15244 & 1696 & 4436 & 1732 & 872 & 720300 & 744280 \\
\hline $\begin{array}{l}\text { Total area } \\
\text { in } 2015\end{array}$ & 347404 & $\begin{array}{c}5513 \\
6\end{array}$ & $\begin{array}{c}32016 \\
4\end{array}$ & 43696 & 31980 & 723924 & $\begin{array}{c}152230 \\
4\end{array}$ \\
\hline $\begin{array}{c}\text { Change } \\
\text { area }\end{array}$ & 22196 & -68 & -2972 & 312 & 888 & -20356 & \\
\hline
\end{tabular}

(1) Characteristics of cultivated land change: In the case of non-water diversion, the cultivated land area increased by $7812 \mathrm{hm}^{2}$, mainly came from the transfer of unused land and forest land, accounting for $86.6 \%$ and $9.4 \%$ of the total transferred area respectively; a few of cultivated land was converted to construction land and unused land. After the implementation of ecological water diversion, the cultivated land area increased by $22196 \mathrm{hm}^{2}$. The increase of cultivated land area was mainly the reclamation of pastureland and unused land, accounting for $27.5 \%$ and $59.9 \%$ respectively. The transferred cultivated land mainly flowed to pastureland, construction land and unused land, accounting for $32.2 \%$, $26.9 \%$ and $24.3 \%$ respectively.

(2) Characteristics of forestland change: In the case of non-water diversion, the area of forestland decreased by $624 \mathrm{hm}^{2}$, and the reduced forestland mainly flowed to cultivated land and unused land, accounting for $27.8 \%$ and $66.5 \%$ respectively. After the implementation of ecological water diversion, the area of forest land was reduced by $68 \mathrm{hm}^{2}$, and the reduced forestland was mainly converted into cultivated land, accounting for $82.3 \%$ of the total outflow area; the unused land was the main source of forest land transfer, accounting for $78.8 \%$ of the total transferred area.

(3) Characteristics of pastureland change: In the case of non-water diversion, the main change path of pastureland area is the mutual transformation between pastureland and unused land. The area transfer out is larger than the area transfer in, and the area of pastureland is reduced by $6060 \mathrm{hm}^{2}$. After the implementation of ecological water transfer, the pastureland area was reduced by $2972 \mathrm{hm}^{2}$, and the reduced grassland mainly flowed to cultivated land and unused land, accounting for $75.0 \%$ and $17.7 \%$ respectively; the main sources of grassland transfer were cultivated land, water surface and unused land, accounting for $16.4 \%, 10.2 \%$ and $69.8 \%$ respectively.

(4) Characteristics of water surface change: In the case of non-water diversion, the main change way of water area is the mutual transformation between the water surface and unused land. The area transfer out is larger than the area transfer in, and the area of water surface decreases by $1284 \mathrm{hm}^{2}$. After the implementation of ecological water diversion, the transferred water area mainly flows to pastureland and unused land, accounting for $31.3 \%$ and $49.4 \%$ respectively; the main source of water diversion is unused land, accounting for $72.7 \%$; the transfer in area is larger than the transfer out, with a net increase of $312 \mathrm{hm}^{2}$.

(5) Characteristics of construction land change: In the case of non-water diversion, the land used for construction was not transferred out, and the land used for conversion was mainly pastureland and unused land, which accounted for $25.2 \%$ and $54.1 \%$ respectively. The area of construction land increased by $444 \mathrm{hm}^{2}$. After the implementation of ecological water diversion, the transferred construction land mainly flows to cultivated land, accounting for $92.8 \%$; the main sources of construction land are cultivated land and unused land, accounting for $43.6 \%$ all; the transfer in area is larger than the transfer out, and the net increase of construction land area is $888 \mathrm{hm}^{2}$.

(6) Characteristics of unused land change :In the case of non-water diversion, unused land reclaimed accounted for $43.7 \%$, and the proportion of land flowing to forestland, pastureland and water was $13.0 \%, 17.8 \%$ and $24.0 \%$ respectively. The main sources of unused land were pastureland and water, accounting for $58.9 \%$ and $29.1 \%$ respectively. After the implementation of ecological water diversion, the unused land transferred mainly to cultivated land and pastureland, accounting for $63.6 \%$ and $18.5 \%$ respectively; the main sources of land use transfer were pastureland and water, accounting for $45.7 \%$ and $28.4 \%$ respectively; the area transfer out is larger than the area transfer in, and the area decreased by $20356 \mathrm{hm}^{2}$. 


\section{Conclusion}

The CLUE-S model of land use change was constructed and used to simulate the spatial pattern of land use in the midstream of Heihe River in 2015 without water diversion. The spatial pattern of land use under natural scenarios and ecological water diversion was compared. The response of land use change to ecological water transfer was analyzed from two aspects: dynamic change land use and land use type conversion. The main conclusions are as follows:

(1)The CLUE-S model can be used to simulate the spatial pattern of land use change in the midstream of Heihe River Basin.

(2) Under both scenarios, cultivated land and construction land area showed an increasing trend, and ecological water transfer aggravated its changing trend; forestland, pastureland and unused land area showed a decreasing trend. Ecological water transfer slowed down the decreasing trend of forestland and pastureland area, and intensified the conversion of unused land to other land use types. In the case of non-water diversion, the water area showed a decreasing trend, however after the implementation of ecological water diversion it showed an increasing trend. After the implementation of ecological water diversion, the speed of land use change in the midstream was accelerated.

(3) In the case of non-water transfer, the dominant types of land use change are cultivated land, pastureland and water, the conversion is mainly with the unused land. After the implementation of ecological water transfer, the dominant types of land use change are cultivated land, pastureland and unused land. The increase of cultivated land is mainly the inflow of pastureland and unused land, and the pastureland mainly flows to pastureland land and unused land. Under the two scenarios, the conversion of land use types shows obvious spatial differences.

\section{Acknowledgments}

This research was supported in part by the National Nature Science Foundation of China (51709237) ,The Science and Technology Plan Project of Department of Water Resources of Zhejiang Province (RA1603), Projects Supported by Zhejiang Provincial Scientific Research Institutes (2017F30009) and National Key R\&D Program of China (2016YFC0401603).

\section{References}

1. L. Youjia, X. Zhongmin, Z. Fanglei. Geogr Res, 30 (3):564-576(2011)

2. Z. Likai, M. Jijun. Prog Geo, 28(5): 782-790(2009)

3. H. Ming, Z. Xuexia, Z. Jianjun. Resour Sci, 34(4): 769-776(2012)

4. M. Libang, L. Shuwen, Y. Lina. Chin J Ecol, 31(7): 1823-1831(2012)

5. S. Sheng, L. Maosong, X. Chi. Chin J Ecol, 27(2) :235-239(2008)
6. L. Chuanzhe, Y. Fuliang, L. Jia. Acta Ecol. Sin, 29(11): 5832-5842(2009)

7. L. Na, Y. Taibao. J Desert Res, 28(2): 223-226(2008)

8. A. Gobin, P. Campling, J. Feyen. AGR ECOSYST ENVIRON, 89(3): 213-228(2002)

9. P. R G, S. L C. AGR ECOSYST ENVIRON, 85(1/3): 239-248(2001)

10. B. Wanqi, Z. Yongmin, Y. Jianzhong. Geogr Res, 24(2): 112-116(2005)

11. R. G Pontius. Photogramm Eng Remote Sensing, 66(8): 1011-1016(2000). 